\title{
Prevalence of Internet Addiction among Higher Secondary Level Students in Kathmandu District
}

\author{
${ }^{1}$ Isha Karmacharya, ${ }^{2}$ Kshitiz Bhujel, ${ }^{1}$ Dipendra Kumar Yadav, ${ }^{3}$ Raj Kumar Subedi

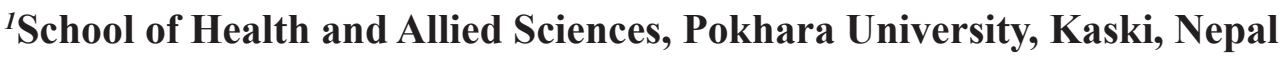 \\ ${ }^{2}$ Kathmandu Medical College Teaching Hospital, Kathmandu, Nepal \\ ${ }^{3}$ Central Institute of Science and Technology (CIST), Kathmandu, Nepal
}

\begin{abstract}
Internet addiction is defined as an impulse control disorder, which is very similar to pathological gambling. It is typically characterized by psychomotor agitation, anxiety, craving depression, hostility, substance experience, preoccupation, loss of control, impairment of function, reduced decision-making ability, and constant online surfing despite negative effects on social and psychological welfare. An institutional based cross-sectional study with a sample comprising of 422 college students (15 - 19 age group) across Kathmandu District was conducted from November $9^{\text {th }}-23^{\text {rd }}, 2014$. Students were assessed with a structured questionnaire and Internet Addiction Test (IAT) scale, which was anonymously selfadministered. The collected data was analyzed with the help of SPSS version 20 and interpreted.

This survey depicts internet penetration rate was $97.3 \%$. The possible addicts/internet addict students were found to spent average of 34 hours per week, compared to the 11 hours of average users. Male students were more possible addicts/internet addicts than female students. This survey found statistically significant difference between average users and possible addicts/internet addicts based on their Family Characteristics which consisted of variables such as economic status $(p=0.001)$, within family relationship $(p=0.009)$, ownership of computer/laptop at home $(p<0.001)$ and loneliness level at home $(p<0.001)$. Based on the interpersonal relationship at college, there was no significant difference between average users and possible/ internet addicts except for the relationship with classmates $(p=0.024)$. Overall, the prevalence of internet addiction among higher secondary level students according to this survey was found to be 2.57. As a result of IAT scale, the prevalence of internet addiction among higher secondary level students of Kathmandu District according to this survey was found to be 2.57.
\end{abstract}

Key words: Adolescent, Internet addiction, Internet Addiction Test, Internet Penetration Rate, Nepal, Prevalence

Corresponding address: Isha Karmacharya, School of Health and Allied Sciences, Pokhara University. E-mail: ishakarmacharya@gmail.com

\section{INTRODUCTION}

Internet addiction (IA) is defined as an impulse control disorder, which does not involve use of an intoxicating drug, and is very similar to pathological gambling. ${ }^{1}$ The term 'Internet addiction' was first used by Dr. Ivan Goldberg (1995) for pathological compulsive internet use. ${ }^{2}$ The other terms to describe negative effects of Internet use include 'compulsive Internet use', 'pathological Internet use', 'Internet dependency' and even 'Internetomania'.

Researchers have related Internet addiction to addictive syndromes similar to impulse-control disorders on the Axis I Scale in the Diagnostic and Statistical Manual of Mental Disorders (DSM), and employed various forms of DSM-IV based criteria to define Internet addiction. ${ }^{3}$ Indeed, IA is currently being considered by the American Psychiatric Association for inclusion in the DSM-V as a psychiatric diagnosis. ${ }^{4}$

Dr. Kimberly Young, who developed the Internet Addiction Test (IAT) and now popularly being used worldwide, suggested the following diagnostic criteria: compulsive tendency to use the Internet, tolerance, withdrawal, unintended excessive use of 
the Internet, continuous desire to use the Internet, decreased interest in other activities and ignorance of the negative effects of excessive Internet use. ${ }^{5}$ Dr. Young linked internet addiction in DSM-IVand adapted the DSM-IV criteria to relate to internet use in IAT. According to her, there are various types of internet addiction such as cyber-sexual addiction, cyber-relationship addiction, net compulsions, information overload, and computer addiction. ${ }^{2}$

Numerous studies have been conducted across the world, especially among adolescents with respect to Internet Addiction. In a study on the prevalence of internet addiction and its association with psychopathology in Indian adolescentsusing Young's original criteria, it identified $24.8 \%$ as possible addicts, and $0.7 \%$ as addicts. ${ }^{2}$ However, there are limited studies done in Nepal, perhaps this growing issue is overshadowed by other health problems in the country. Thus, the aim of this study was to explore the prevalence of internet addiction among higher secondary level students in Kathmandu district.

\section{METHODS}

An institution based cross-sectional study design was carried out among secondary level students aged $15-19$ years of six colleges $(10 \%$ out of 56 colleges in Kathmandu district which consists of large number of higher secondary schools with high student density). ${ }^{6}$ Purposive sampling was applied to select the Ten plus two colleges and convenient selection of classes was done. Census method was applied to select the students. The surplus data were considered for entry and analysis.

The total sample size of the study, calculated using Fishers' formula $\mathrm{n}=\mathrm{Z}^{2} \mathrm{pq} / \mathrm{d}^{2}$ and assuming $50 \%$ prevalence of internet addiction among adolescents, allowable error \pm 0.05 at 95 percent confidence level, $10 \%$ as non-response rate, was 422 .

The study tool was primarily adapted from the Internet Addiction Test (IAT) questionnaire developed by Dr. Kimberly Young. The Internet Addiction Test (IAT) is a 20 -item 5-point Likert scale that measures the severity of self-reported compulsive use of the internet. ${ }^{5}$ Total internet addiction scores are calculated, with possible scores for the sum of 20 items ranging from 20 to 100 . According to Young's criteria, total IAT scores $20-49$ represent average internet users with complete control of their internet use, $50-79$ represent over-users with occasional or frequent problems caused by their internet use, and $80-$ 100 represent internet addicts with significant problems caused by their internet use. Further the IAT scores was categorized into average internet users $(20-49)$ and possible addicts/internet addicts $(50-100)$.

Approval from Nepal Health Research Council was obtained. The written informed consent was taken from the HSEB of Kathmandu, six colleges and respondents. The participants were well informed about the purpose and objectives of the study and voluntary participation.

Anonymous self- administered questionnaire was used as technique for data collection in this study. The data collection was carried out within 15 days, from November $12^{\text {th }}-23^{\text {rd }}, 2014$.

The data was entered in EpiData version 3.1. Data were categorized into similar attributes. All the data were imported to SPSS version 22 and analysis was done accordingly. Univariate analysis; was done to analyze frequency of different demographic, socioeconomic characteristics. Bivariate analysis was done to cross tabulate different independent variables with dependent variables in order to determine the association between them.

\section{RESULTS}

Out of 440 respondents, $215(48.9 \%)$ were male and $225(51.1 \%)$ of them were female. Upper caste (Brahmins and Chettris) were predominant by ethnicity, i.e. $57 \%$. This survey revealed that more than half of the respondents $(64.5 \%)$ had heard of Internet Addiction whereas, the rest respondents had not heard of Internet Addiction. Among those who had heard of IA, $83.8 \%$ were not aware of the effects of IA and even those who claimed to know the effects of IA, i.e. $16.2 \%$, of them did not know the major effects like depression, social-phobia, sleep disorders, etc.

The internet penetration rate among the students was $97.3 \%$ whereas, only $2.7 \%$ had never used 
internet. The prevalence of internet addiction was found to be 2.57 (Table 1).

Table 1: Internet Addiction Level

\begin{tabular}{|l|c|c|}
\hline IAT Score Category & Frequency & Percent \\
\hline Average users & 281 & 65.65 \\
\hline Over users & 136 & 31.78 \\
\hline Internet addicts & 11 & 2.57 \\
\hline Total & 428 & 100.0 \\
\hline Average users $(281,65.65 \%)$ & \\
\hline \multicolumn{2}{|l|}{ Possible Addicts /Internet Addicts $(136+11=147,34.35 \%)$} \\
\hline
\end{tabular}

Out of the responses given by 428 internet users, majority of the students had internet access at home i.e. $82.1 \%$, followed by $12.9 \%$ at cyber and
$5.1 \%$ at college. Among the internet users, $60.7 \%$ had computer/laptop with internet access in their room. Majority of the students used mobile phones for internet use i.e. $52.7 \%$.

The observed difference of Internet Addiction Level between male and female students was statistically significant $(p=0.001)$. Likewise by ethnicity, economic status, within family relationship, ownership of computer/laptop at home, loneliness level at home, and relationship with classmates, the observed difference of Internet Addiction Level was found to be statistically significant as shown in Table 2.

Table 2: Association between Internet Addiction Level and Independent Variables

\begin{tabular}{|c|c|c|c|c|c|c|c|c|}
\hline \multirow{2}{*}{\multicolumn{2}{|c|}{ Characteristics }} & \multicolumn{2}{|c|}{ Total $n=428$} & \multicolumn{2}{|c|}{ Average Users } & \multicolumn{2}{|c|}{$\begin{array}{l}\text { Possible Addicts/ } \\
\text { Internet Addicts }\end{array}$} & \multirow[b]{2}{*}{ p-value } \\
\hline & & $\mathbf{n}$ & $\%$ & $\mathbf{N}$ & $\%$ & $\mathbf{N}$ & $\%$ & \\
\hline \multirow{2}{*}{ Sex } & Male & 213 & 49.76 & 124 & 58.22 & 89 & 41.78 & \multirow{2}{*}{0.001} \\
\hline & Female & 215 & 50.23 & 157 & 73.02 & 58 & 26.98 & \\
\hline \multirow{7}{*}{ Ethnicity } & Brahmin & 130 & 30.37 & 99 & 76.15 & 31 & 23.85 & \multirow{7}{*}{0.038} \\
\hline & Chhettri & 111 & 25.93 & 71 & 63.96 & 40 & 36.04 & \\
\hline & Tharu & 14 & 3.27 & 10 & 71.43 & 4 & 28.57 & \\
\hline & Magar & 18 & 4.21 & 13 & 72.22 & 5 & 27.78 & \\
\hline & Newar & 85 & 19.86 & 51 & 60.00 & 34 & 40.00 & \\
\hline & Dalit & 9 & 2.10 & 5 & 55.56 & 4 & 44.44 & \\
\hline & Others & 61 & 14.25 & 32 & 52.46 & 29 & 47.54 & \\
\hline \multirow{5}{*}{ Economic Status } & $\begin{array}{l}\text { Rather } \\
\text { wealthy }\end{array}$ & 33 & 7.71 & 16 & 48.48 & 17 & 51.52 & \multirow{5}{*}{0.001} \\
\hline & $\begin{array}{l}\text { Medium } \\
\text { wealthy }\end{array}$ & 159 & 37.15 & 94 & 59.12 & 65 & 40.88 & \\
\hline & Medium & 217 & 50.70 & 161 & 74.19 & 56 & 25.81 & \\
\hline & Medium low & 17 & 3.97 & 10 & 58.82 & 7 & 41.18 & \\
\hline & Rather poor & 2 & 0.47 & 0 & 0.00 & 2 & 100.00 & \\
\hline \multirow{4}{*}{$\begin{array}{l}\text { Within Family } \\
\text { relationship }\end{array}$} & Very good & 234 & 54.67 & 165 & 70.51 & 69 & 29.49 & \multirow{4}{*}{0.009} \\
\hline & Good & 149 & 34.81 & 95 & 63.76 & 54 & 36.24 & \\
\hline & Satisfactory & 40 & 9.35 & 20 & 50.00 & 20 & 50.00 & \\
\hline & Poor & 5 & 1.17 & 1 & 20.00 & 4 & 80.00 & \\
\hline \multirow{2}{*}{$\begin{array}{l}\text { Computer/ } \\
\text { laptop in room }\end{array}$} & Yes & 260 & 60.75 & 147 & 56.54 & 113 & 43.46 & \multirow{2}{*}{$<0.001$} \\
\hline & No & 168 & 39.25 & 134 & 79.76 & 34 & 20.24 & \\
\hline \multirow{3}{*}{$\begin{array}{l}\text { Loneliness level } \\
\text { at home }\end{array}$} & Much & 40 & 9.35 & 20 & 50.00 & 20 & 50.00 & \\
\hline & Little & 234 & 54.67 & 134 & 57.26 & 100 & 42.74 & \multirow{2}{*}{$<0.001$} \\
\hline & None & 154 & 35.98 & 127 & 82.47 & 27 & 17.53 & \\
\hline \multirow{5}{*}{$\begin{array}{l}\text { Relationship } \\
\text { with teachers }\end{array}$} & Very good & 87 & 20.33 & 54 & 62.07 & 33 & 37.93 & \multirow{5}{*}{0.896} \\
\hline & Good & 226 & 52.80 & 152 & 67.26 & 74 & 32.74 & \\
\hline & Satisfactory & 106 & 24.77 & 69 & 65.09 & 37 & 34.91 & \\
\hline & Poor & 7 & 1.64 & 5 & 71.43 & 2 & 28.57 & \\
\hline & Very poor & 2 & 0.47 & 1 & 50.00 & 1 & 50.00 & \\
\hline
\end{tabular}




\begin{tabular}{|l|l|r|r|r|r|r|r|r|}
\hline \multirow{4}{*}{$\begin{array}{l}\text { Relationship } \\
\text { with classmates }\end{array}$} & Very good & 201 & 46.96 & 133 & 66.17 & 68 & 33.83 & \\
\cline { 2 - 8 } & Good & 177 & 41.36 & 124 & 70.06 & 53 & 29.94 & \multirow{3}{*}{0.024} \\
\cline { 2 - 8 } & Satisfactory & 46 & 10.75 & 23 & 50.00 & 23 & 50.00 & \\
\cline { 2 - 8 } & Poor & 4 & 0.93 & 1 & 25.00 & 3 & 75.00 & \\
\hline \multirow{2}{*}{$\begin{array}{l}\text { No. of close } \\
\text { friends }\end{array}$} & 1 to 2 & 108 & 25.23 & 70 & 64.81 & 38 & 35.19 & \\
\cline { 2 - 8 } & 3 to 6 & 163 & 38.08 & 110 & 67.48 & 53 & 32.52 & \multirow{2}{*}{0.82} \\
\cline { 2 - 8 } $\begin{array}{l}\text { Loneliness level } \\
\text { at college }\end{array}$ & M or more & 157 & 36.68 & 101 & 64.33 & 56 & 35.67 & \\
\cline { 2 - 8 } & Little & 200 & 46.73 & 127 & 63.50 & 73 & 36.50 & \multirow{2}{*}{0.145} \\
\cline { 2 - 8 } & None & 198 & 46.26 & 138 & 69.70 & 60 & 30.30 & \\
\hline
\end{tabular}

The study revealed that students spent about 3 hours per day and spent $\$ 6.35$ per month in average on internet (Table 3). 35.9\% respondents used internet for social networking, followed by entertainment $(32.4 \%)$, education $(21.4 \%)$, online gaming $(7.3 \%)$, online buying/selling $(1.6 \%)$ and online job (1.4\%). The possible addicts/internet addicts spent nearly three times the number of hours per week online and about two times the money spent per month on internet than the average users.

Table 3: Online Daily and Money Spent on Internet based on Internet Addiction Level

\begin{tabular}{|l|c|c|c|}
\hline & Total (Mean) & Average Users (Mean) & Possible Addicts/Internet Addicts (Mean) \\
\hline Online daily (in hrs) & 3 & 1.58 & 4.82 \\
\hline Money spent monthly (in \$) & 6.35 & 4.63 & 9.63 \\
\hline
\end{tabular}

Among internet users, 55.6\% feared that life without the Internet would be boring, empty, and joyless, $42.1 \%$ found themselves saying "just a few more minutes" when online, whereas, $33.4 \%$ tried to cut down the amount of time spend online and failed, and $21.0 \%$ lost sleep due to late-night log-ins (Table 4).

Table 4: Score Percentage of Internet Addiction Test by Internet Users

\begin{tabular}{|c|c|c|c|c|c|}
\hline $\begin{array}{l}\text { Situations } \\
\text { (Note: } 0=\text { Doesn't Apply; } 1=\text { Rarely; } 2=\text { Occasionally; } 3=\text { Frequently;4-5 = Often } / \\
\text { Alwavs) }\end{array}$ & $\begin{array}{c}\mathbf{0} \\
(\%)\end{array}$ & $\begin{array}{c}1 \\
(\%)\end{array}$ & $\begin{array}{c}2 \\
(\%)\end{array}$ & $\begin{array}{c}3 \\
(\%)\end{array}$ & $\begin{array}{l}4-5 \\
(\%)\end{array}$ \\
\hline 1. Stay online longer than intended & 6.3 & 24.8 & 21.0 & 18.7 & 29.2 \\
\hline 2. Neglect household chores to spend more time on-line & 20.1 & 34.8 & 18.7 & 10.5 & 15.9 \\
\hline 3. Excitement of the Internet to intimacy with the partner? & 39.5 & 17.5 & 12.1 & 9.8 & 21.0 \\
\hline 4. Form new relationships with fellow on-line users & 24.3 & 31.3 & 16.4 & 10.0 & 18.0 \\
\hline 5. Others in life complain about the amount of time spend on-line & 14.7 & 27.8 & 15.4 & 12.4 & 29.7 \\
\hline 6. Grades or college works suffer because of the amount of time spend on-line & 29.0 & 31.3 & 16.1 & 11.0 & 12.6 \\
\hline 7. Check e-mail before something else that need to do & 19.2 & 19.4 & 18.5 & 14.0 & 29.0 \\
\hline 8. Job performance or productivity suffer because of the Internet & 51.2 & 21.0 & 12.4 & 8.2 & 7.2 \\
\hline 9. Become defensive or secretive when anyone asks you what you do on-line & 27.8 & 25.5 & 18.2 & 12.6 & 15.9 \\
\hline 10. Block out disturbing thoughts about life with soothing thoughts of the Internet & 23.6 & 23.1 & 12.4 & 13.1 & 27.8 \\
\hline 11. Find yourself anticipating when you will go on-line again & 21.5 & 25.7 & 13.1 & 17.5 & 22.2 \\
\hline 12. Fear that life without the Internet would be boring, empty, and joyless & 9.1 & 10.5 & 10.0 & 14.7 & 55.6 \\
\hline 13. Snap, yell, or act annoyed if someone bothers you while you are on-line & 13.6 & 26.2 & 14.0 & 17.1 & 29.2 \\
\hline
\end{tabular}




\begin{tabular}{|l|r|r|r|r|r|}
\hline 14. Lose sleep due to late-night log-ins & 22.9 & 25.7 & 17.8 & 12.6 & 21.0 \\
\hline 15. Feel preoccupied with the Internet when off-line, fantasize about being on-line & 36.2 & 21.7 & 15.0 & 12.1 & 15.0 \\
\hline 16. Find yourself saying "just a few more minutes" when online & 7.9 & 18.7 & 16.1 & 15.2 & 42.1 \\
\hline 17. Try to cut down the amount of time you spend on-line and fail & 16.1 & 20.3 & 12.6 & 17.5 & 33.4 \\
\hline 18. Hide how long you've been on-line & 25.2 & 27.8 & 17.8 & 16.4 & 12.9 \\
\hline 19. Spend more time on-line over going out with others & 43.5 & 22.9 & 14.3 & 12.1 & 7.2 \\
\hline $\begin{array}{l}\text { 20. Feel depressed, moody or nervous when you are off-line, which goes away once you are } \\
\text { back on-line }\end{array}$ & 39.5 & 24.1 & 12.6 & 10.7 & 13.1 \\
\hline
\end{tabular}

In comparison to average users, possible addicts/ internet addicts found dramatically more often or always in all the situations mentioned in Table 5. Out of 147 possible addicts/internet addicts, $83 \%$ found themselves saying often or always "just a few more minutes" when online, almost 78\% often or always feared that life without the internet would be boring, empty, and joyless and nearly $48 \%$ often or always lost sleep due to late-night log-ins. Thus, the study revealed possible addicts/ internet addict students were highly dependent to internet.

Table 5: Comparison between Average Users and Possible Addicts/Internet Addicts by IAT

\begin{tabular}{|l|c|c|}
\hline Situations & $\begin{array}{c}\text { Average } \\
\text { users }\end{array}$ & $\begin{array}{c}\text { Possible Addicts/ } \\
\text { Internet Addicts } \\
\text { (Note: 4-5 = Often/Always) }\end{array}$ \\
\cline { 2 - 3 } & $\mathbf{( 4 - 5 ) ~ \%}$ & 57.1 \\
\hline Stay on-line longer than intended & 14.6 & 63.3 \\
\hline Others in life complain about the amount of time spend on-line & 12.1 & 57.8 \\
\hline Block out disturbing thoughts about life with soothing thoughts of the Internet & 12.1 & 55.8 \\
\hline Find yourself anticipating when you will go on-line again & 4.6 & 77.6 \\
\hline Fear that life without the Internet would be boring, empty, and joyless & 44.1 & 60.5 \\
\hline Snap, yell, or act annoyed if someone bothers you while you are on-line & 12.8 & 47.6 \\
\hline Lose sleep due to late-night log-ins & 7.1 & 83.0 \\
\hline Find yourself saying "just a few more minutes" when online & 20.6 & 67.3 \\
\hline Try to cut down the amount of time you spend on-line and fail & 15.7 & \\
\hline
\end{tabular}

\section{DISCUSSION}

Numerous studies have explored the relationships among heavy Internet use, social-psychological factors, and computer-related factors. ${ }^{7}$ In Young's study $^{8}$, compared to the 5 hours of non-dependents, internet addicts reported a striking average of 39 hours per week spent online. Similarly, Chen and Chou (1999) reported the high-risk group spent an average of 20 hours per week online; the nonhigh-risk group spent about 9 hours online. ${ }^{7}$ From this survey, possible addict/internet addict students were found to spent average of 34 hours per week, compared to the 11 hours of average users.

Several studies have indicated that gender is one of the predicting factors in Internet addiction, that is, males are more likely than females to become Internet addicts. ${ }^{2,}$ 7-9 This study also showed that male students were more possible addicts/ internet addicts than female students. Interactive online games and contents mainly rely on power, dominance, control, and/or violence, this may explain males attraction to internet use than females. $^{8}$

Several studies indicate adolescents with IA were significantly more likely to have dysfunctional familial relationships. ${ }^{10-13}$ This survey also found statistically significant difference between average users and possible addicts/internet addicts based on their Family Characteristics.

A pilot study found there was significant difference between male and female addicts in association with the number of close friends $(p<0.001) .{ }^{4}$ In contrast, this study shows there was no significant difference between average users and possible addicts/internet addicts in association with the number of close friends but statistical significant 
difference was seen based on the relationship with classmates $(\mathrm{p}=0.024)$ similar to other studies. ${ }^{14,15}$

Additionally, from this survey it reveals, $83 \%$ of possible addicts/internet addicts find themselves saying often/always "just a few more minutes" when online, almost $78 \%$ often/always fear that life without the internet would be boring, empty, and joyless, $67.3 \%$ often/always try to cut down the amount of time you spend online and fail, more than half of them (57.1\%) stay online longer than intended. Thus, this shows possible addicts/ internet addict students are highly dependent to the internet. A study conducted in US in University students, sleep deprivation and general physical complaints are considered associated features of Internet addiction. ${ }^{16}$ Similarly, this survey reveals nearly 5 in 10 possible addicts/internet addicts often/ always lose sleep due to late-night log-ins.

Dr. Young study has concluded that suspected cases of Problematic Internet Use (PIU) should undergo depression assessment. ${ }^{3}$ Although it is not evident whether depression leads to the development of internet abuse or it is a consequence, yet assessment of the same is imperative. ${ }^{2}$ Young showed that withdrawal from significant real-life relationships is a consequence of pathological internet users. ${ }^{3}$

Nemiz et al. study showed that students with PIU had low self-esteem and were socially inhibited online. $^{2}$

Dr. Kimberly describes common signs and numerous effects of Internet addiction, however, the diagnosis of Internet addiction can be challenging. ${ }^{3}$ Considering so many practical uses and several direct benefits of the Internet for advancement in this modern world, signs of addiction can be potentially masked. Thus internet can escape the criticism of being addictive, which makes it an emerging issue worldwide.

More than 30 million Internet gamers were said to be addicted in China. It was considered as an epidemic, and to battle this problem Internet cafes were regularly shut down and those illegally operated were charged huge fines for their operators, laws were introduced to restrict the number of hours adolescents can play online games and the first treatment center for Internet addiction was opened in Beijing in 2005. ${ }^{7}$
Overall, majority of the researches have targeted adolescent population, and results concerning the prevalence of Internet Addiction among adolescents are significant. Majority of the researches worldwide reveal about the effects of IA on mental health focusing on the adolescent population and advocate about drawing attention on this issue.

\section{CONCLUSION}

Although Internet addiction is a relatively new phenomenon, it has already become a subject of numerous studies. Internet penetration rate is gradually rising in Nepal, but the study on Internet Addiction has not yet been prioritized. Thus, this study is a preliminary step toward understanding the extent of internet addiction among +2 level students in Kathmandu district.The prevalence of internet addiction among higher secondary level students according to this survey was 2.57 with internet penetration rate $97.3 \%$. The possible addicts/internet addict students were found to spent average of 34 hour per week, compared to the 11 hours of average users. Male students were more possible addicts/internet addicts than female students. The purpose of internet use was majorly for social networking and entertainment. This survey reveals that more than half of the respondents have heard of Internet Addiction i.e. $284(64.5 \%)$, whereas, the rest 46 respondents i.e. $35.5 \%$ have not heard of Internet Addiction. Among those who heard of IA, 83.8\% were not aware of the effects of IA. However, the results cannot be generalized at large and cannot represent all age group of adolescents. Thus, further research studies are required to understand the underlying mechanisms of internet addiction and its various factors and to explore effective preventative or interventional strategies.

\section{REFERENCES}

1. Bozkurt H, Coskun M, Ayaydin H, Adak I and Zoroglu SS. Prevalence and patterns of psychiatric disorders in referred adolescents with Internet addiction. Psychiatry Clin Neurosci. 2013; 67: 352-9.

2. Goel D, Subramanyam A and Kamath R. A study on the prevalence of internet addiction and its association with psychopathology in 
1. Indian adolescents. Indian J Psychiatry. 2009; 55: 140-3.

2. Young DK. Assessment of Internet Addiction. The Center for Internet Addiction Recovery.

3. Fu KW, Chan WS, Wong PW and Yip PS. Internet addiction: prevalence, discriminant validity and correlates among adolescents in Hong Kong. Br J Psychiatry. 2010; 196: 48692.

4. Cho H, Kwona M, Choi J-H, et al. Development of the Internet addiction scale based on the Internet Gaming Disorder criteria suggested in DSM-5. 2014.

5. CTF Nepal. A Study on Achievements and Effectiveness of Higher Secondary Schools Enhancement Program (HSSEP) 2014.

6. Chou C, Condron L and Belland JC. A Review of the Research on Internet Addiction. $2005 ; 17$.

7. Young KS. Internet addiction: The emergence of a new clinical disorder. Cyberpsychol. Behav. 1998; 1: 237-44.

8. Liang L, Zhou D, Yuan C, Shao A and Bian Y. Gender differences in the relationship between internet addiction and depression: A cross-lagged study in Chinese adolescents. Computers in Human Behavior. 2016; 63: 463-70.
9. Tsitsika A, Critselis E, Louizou A, et al. Determinants of Internet addiction among adolescents: a case-control study. ScientificWorldJournal. 2010; 11: 866-74.

10. Park SK, Kim JY and Cho CB. Prevalence of Internet addiction and correlations with family factors among South Korean adolescents. Adolescence. 2008; 43: 895-909.

11. Lam LT, Peng Z-w, Mai J-c and Jing J. Factors Associated with Internet Addiction among Adolescents. CyberPsychology \& Behavior. 2009; 12: 551-5.

12. Wu CST, Wong HT, Yu KF, et al. Parenting approaches, family functionality, and internet addiction among Hong Kong adolescents. BMC Pediatrics. 2016; 16: 130.

13. S. MG. Social Relationships and Internet Use among Adolescents in Israel. Social Science Quarterly. 2001; 82: 329-39.

14. Selfhout MHW, Branje SJT, Delsing M, ter Bogt TFM and Meeus WHJ. Different types of Internet use, depression, and social anxiety: The role of perceived friendship quality. Journal of Adolescence. 2009; 32: 819-33.

15. Li W, O'Brien JE, Snyder SM and Howard MO. Characteristics of Internet Addiction/ Pathological Internet Use in U.S. University Students: A Qualitative-Method Investigation. PLoS ONE. 2015; 10: e0117372. 